\title{
Clinical anatomy of the cephalic vein for safe performance of venipuncture
}

\author{
Mitsuhiro Matsuo ${ }^{1^{*}}$ (D), Satoru Honma ${ }^{2}$, Takahiro Sonomura ${ }^{2}$ and Mitsuaki Yamazaki ${ }^{1}$
}

\begin{abstract}
Background: The aims of this study were to elucidate why the cephalic vein provides a reliable cannulation site from a morphological viewpoint and identify an effective landmark for avoiding injury to the superficial branch of the radial nerve (SBRN), allowing for safe venipuncture of the cephalic vein.

Findings: We examined 32 forearms and wrists from 18 cadavers. The cephalic vein was a constant structure containing a branch communicating with a collateral vein of the deep palmar arch via the first dorsal interossei muscle. The metacarpal vein from the medial two digits flowed into the cephalic vein. The venous confluence formed $5.8 \pm 1.2 \mathrm{~cm}$ proximal to the radial styloid process. The SBRN passed $0.4 \pm 0.3 \mathrm{~cm}$ volar to the venous confluence. The distance between the venous confluence and subcutaneous emergence of the SBRN was $2.6 \pm 1$. $0 \mathrm{~cm}$.

Conclusions: These observations suggest that the cephalic vein is a constant structure that serves as a drainage vein of the hand and provides a reliable cannulation site in the forearm. The venous confluence may serve as a novel landmark to predict the running course of the SBRN.
\end{abstract}

Keywords: Cephalic vein, Superficial branch of the radial nerve, Venipuncture, Nerve injury

\section{Findings Introduction}

The cephalic vein, which passes the anatomical snuff box in the wrist, is one of the most frequently selected sites in the distal forearm for venous cannulation in Japan [1]. The superficial branch of the radial nerve (SBRN), which runs close to the cephalic vein, exhibits various bifurcation patterns $[2,3]$. The point at which the cephalic vein crosses the SBRN is highly variable [4]. Therefore, there is a risk of nerve injury when puncturing the cephalic vein and subsequent development of causalgia or neuromas $[5,6]$. Although the cephalic vein should not be selected for the first puncture attempt, this vein can provide a reliable cannulation site when it is difficult to obtain other venous access [7]. In this study, we performed cadaveric dissection to elucidate why the cephalic vein provides a reliable cannulation site from a morphological viewpoint and identify an effective

\footnotetext{
* Correspondence: matsuo@itoigawa-hp.jp

1 Department of Anesthesiology, Faculty of Medicine, University of Toyama,

2630 Sugitani, Toyama 930-0194, Japan

Full list of author information is available at the end of the article
}

landmark with which to avoid injury to the SBRN, thus ensuring safe venipuncture of the cephalic vein.

\section{Materials and methods}

This study was approved by the Ethical Committee of Kanazawa Medical University (no. E211). We examined 32 forearms and wrists from 18 cadavers (12 males, 6 females) with no known trauma or disease in the upper limbs. All cadavers had been donated to Kanazawa Medical University for medical education. The mean age of the cadavers was 80 years. Distance measurements were made (Fig. 1), and the data are shown as the mean \pm standard deviation of 31 forearms.

\section{Results}

The cephalic vein, which ran over the anatomical snuff box, was identified in all arms. As shown in Fig. 1, each cephalic vein had a branch that communicated with a collateral vein of the deep palmar arch via the first dorsal interosseous muscle in 32 of 32 cases (100\%). Although cutaneous veins are generally derived only from the skin, the cephalic vein is also derived from the hand. In contrast to the cephalic vein, no cutaneous 

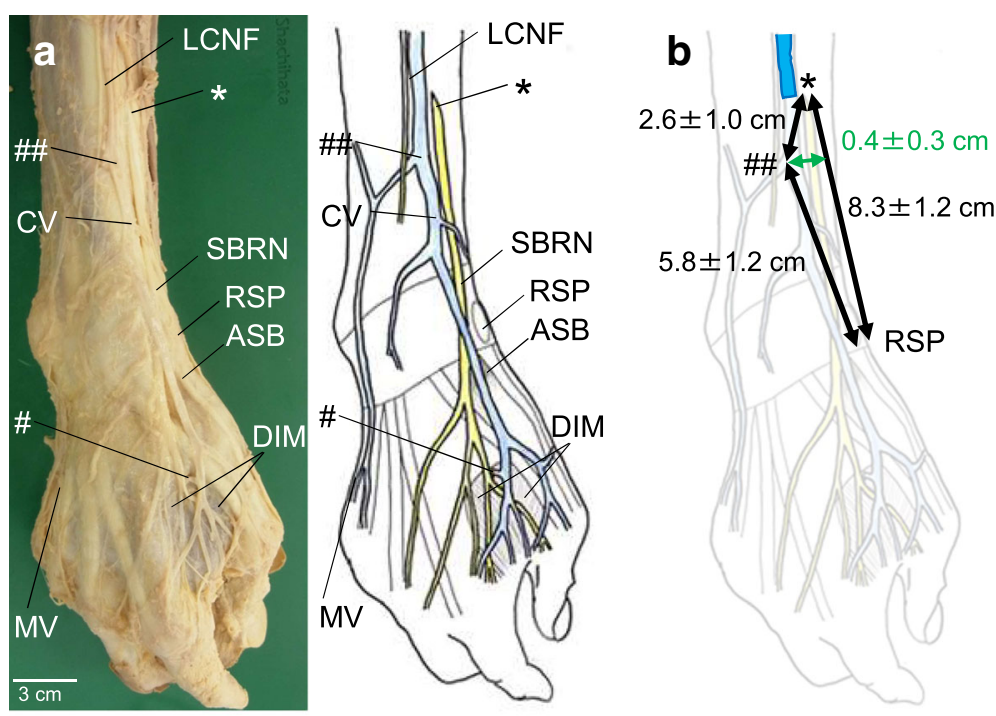

Fig. 1 Gross anatomy of the cephalic vein and superficial branch of the radial nerve (SBRN). a Macroscopic appearance of the forearm. $\mathbf{b}$ Distance between radial styloid process (RSP) $\left(^{*}\right.$ to \#\#) is shown as mean \pm standard deviation. Blue area shows a suggestive safe area for cannulation to the CV. ASB anatomical snuff box, CV cephalic vein, DIM first dorsal interossei muscle, LCNF lateral cutaneous nerve of the forearm, MV metacarpal vein. "Communicating branch of CV to deep palmar vein. ${ }^{\# \# C o n f l u e n c e ~ o f ~ C V ~ a n d ~ m e t a c a r p a l ~ v e i n . ~}{ }^{*}$ Emergence of SBRN

veins in the present study had branches that directly connected to the deep palmar vein. The SBRN emerged from under the brachioradialis and coursed between the tendons of the extensor carpi radialis longus and the brachioradialis in 31 of 32 cases (97\%). In one arm, the SBRN was lacking, and the lateral cutaneous nerve of the forearm derived from the musculocutaneous nerve compensated for its absence. The SBRN emerged at a mean distance of $8.3 \pm 1.2 \mathrm{~cm}$ (range, $5.5-10.4 \mathrm{~cm}$ ) proximal to the radial styloid process. The metacarpal vein from the medial two digits flowed into the cephalic vein. The venous confluence formed $5.8 \pm 1.2 \mathrm{~cm}$ (range, $4.1-7.8 \mathrm{~cm}$ ) proximal to the radial styloid process. The SBRN passed $0.4 \pm 0.3 \mathrm{~cm}$ (range, $0.0-1.0 \mathrm{~cm}$ ) volar to the venous confluence. The distance between the venous confluence and subcutaneous emergence of the SBRN was $2.6 \pm 1.0 \mathrm{~cm}$ (range, $0.7-4.6 \mathrm{~cm}$ ). The SBRN ran beside the cephalic vein in the distal forearm and crossed the inferior aspect of the cephalic vein in all arms that possessed the SBRN.

\section{Discussion}

In this study, we revealed that the cephalic vein is consistently derived from a collateral vein of the deep palmar arch. These observations suggest that the cephalic vein exists constantly because of a drainage vein of the hand. Interestingly, the communicating branch is illustrated in anatomy textbooks such as Grant's Atlas of Anatomy [8] and Toldt-Hochstetter Anatomischer Atlas [9], but it is not documented in detail. Unlike other unnamed cutaneous veins which show a variety of running courses, the cephalic vein constantly exists and seems to provide a reliable cannulation site in the distal forearm.

The point at which the SBRN emerges in the subcutaneous fat was at a mean of $8.3 \mathrm{~cm}$ from the radial styloid process in this study using Japanese cadavers, which is consistent with previous studies [2-4]. It is likely that the distance from emergence of the SBRN to the radial styloid process is not affected by sex or ethnicity [10]. In addition to the radial styloid process, the dorsal tubercle of the radius is another bony landmark. Robson et al. [2] reported that the SBRN passes $1.49 \mathrm{~cm}$ radial to the dorsal tubercle of the radius. In the present study, the venous landmark (confluence of the cephalic vein from the ulnar-side metacarpal vein) was $2.6 \mathrm{~cm}$ (range, $0.7-4.6 \mathrm{~cm}$ ) distal to the emergence of the SBRN and $0.4 \mathrm{~cm}$ volar to passing the nerve. In other words, the cephalic vein at a point $\geq 4.6 \mathrm{~cm}$ proximal to the venous confluence should be selected as the cannulation site to avoid injury to the SBRN. Consistent with these observations, the figures in previous reports $[2,4,11]$ show that the SBRN passes just under or volar to the venous confluence. Further studies are needed to confirm the availability of the venous confluence as a visible landmark for cephalic vein cannulation.

The SBRN ran beside the cephalic vein in the distal forearm and crossed the inferior aspect of the cephalic vein in this study, which is consistent with a previous investigation [4]. Vialle et al. also have showed that the crossing point ranged from $9 \mathrm{~cm}$ proximally from the radial styloid process [4]. In case the cephalic vein is selected as the venous cannulation site, penetration of 
the posterior wall of the cephalic vein must be avoided. Additionally, as noted in case series describing iatrogenic SBRN injury [6], the use of a 22-gauge or smaller needle might be helpful to avoid significant nerve injury. The lateral cutaneous nerve of the forearm, the diameter of which is smaller than that of the SBRN, often runs over the cephalic vein (Fig. 1). Although no reports have described lateral antebrachial cutaneous nerve injury in the distal forearm, the nerve can also be injured following cephalic vein cannulation.

Besides nerve injury, arterial injury is also reported a less common complication when puncturing the cephalic vein $[12,13]$. The arterial injury may occur only when the superficial radial artery is present. The superficial radial artery is an anatomic variation of the radial artery which running over the anatomical snuffbox, and its frequency has been reported as $0.5-1 \%$ [12].

\section{Conclusion}

In summary, this study addressed the morphological reason why the cephalic vein provides a reliable cannulation site and identified a superficial landmark with which to avoid SBRN injury. There is a substantial risk of SBRN nerve injury when puncturing the cephalic vein. In case the cephalic vein is selected as the venous cannulation site, the cephalic vein at a point $\geq 4.6 \mathrm{~cm}$ proximal to the venous confluence should be selected as the cannulation site to avoid injury to the SBRN. Although a limitation of this study is the small number of cadavers in the dissection series, these findings may contribute to safe venipuncture of the cephalic vein.

Funding

None.

\section{Authors' contributions}

MM, SH, and TS designed and performed the research; MY directed the study and was involved in manuscript preparation. All authors read and approved the final manuscript.

Ethics approval and consent to participate

This study was approved by the Ethical Committee of Kanazawa Medical University (no. E211)

\section{Competing interests}

The authors declare that they have no competing interests.

\section{Publisher's Note}

Springer Nature remains neutral with regard to jurisdictional claims in published maps and institutional affiliations.

\section{Author details}

'Department of Anesthesiology, Faculty of Medicine, University of Toyama, 2630 Sugitani, Toyama 930-0194, Japan. ${ }^{2}$ Anatomy II, Kanazawa Medical University, Uchinada, Japan.
Received: 3 August 2017 Accepted: 5 September 2017

Published online: 11 September 2017

References

1. Kurita A, Hara Y, Ota K, Shinozaki E, Tamegawa Y, Fujii T. Anatomical knowledge needed for nurses to perform intravenous injection safly (in Japanese). Keitai Kinou. 2015;13:71-8.

2. Robson AJ, See MS, Ellis H. Applied anatomy of the superficial branch of the radial nerve. Clin Anat. 2008:21:38-45.

3. Ikiz ZA, Uçerler $\mathrm{H}$. Anatomic characteristics and clinical importance of the superficial branch of the radial nerve. Surg Radiol Anat. 2004:26:453-8.

4. Vialle R, Pietin-Vialle C, Cronier P, Brillu C, Villapadierna F, Mercier P. Anatomic relations between the cephalic vein and the sensory branches of the radial nerve: how can nerve lesions during vein puncture be prevented? Anesth Analg. 2001;93:1058-61.

5. Kretschmer T, Antoniadis G, Braun V, Rath SA, Richter HP. Evaluation of iatrogenic lesions in 722 surgically treated cases of peripheral nerve trauma. J Neurosurg. 2001;94:905-12

6. Sawaizumi T, Sakamoto A, Ito H. Injury of superficial radial nerve on the wrist joint induced by intravenous injection. J Nippon Med Sch. 2003;70:355-9.

7. Putensen D, Pilcher L, Collier D, McInerney K. Ultrasound-guided peripheral deep vein cannulation to perform automated red cell exchange-a pilot study in a single centre. J Clin Apher. 2016;31:501-6.

8. AMR A, Dalley AF II. Grant's Atlas of Anatomy. 11th ed. Baltimore: Lippincott Williams \& Wilkins; 2005.

9. Heinrich H. Toldt-Hochstetter Anatomischer Atlas. München: Urban \& Schwarzenberg; 1973.

10. Kim $\mathrm{KH}$, Byun $\mathrm{EJ}$, Oh EH. Ultrasonographic findings of superficial radial nerve and cephalic vein. Ann Rehabil Med. 2014;38:52-6.

11. Gupta R, Aggarwal A, Sahni D, Harjeet K, Barnwal M. Anatomical survey of terminal branching patterns of superficial branch of radial nerve in fetuses. Surg Radiol Anat. 2012;34:415-20.

12. Lirk P, Keller C, Colvin J, Colvin H, Rieder J, Maurer H, Moriggl B. Unintentional arterial puncture during cephalic vein cannulation: case report and anatomical study. $\mathrm{Br}$ J Anaesth. 2004:92:740-2.

13. Shivappagoudar VM, George B. Unintentional arterial cannulation during cephalic vein cannulation. Indian J Anaesth. 2013:57:320-2.

\section{Submit your manuscript to a SpringerOpen ${ }^{\circ}$ journal and benefit from:}

- Convenient online submission

- Rigorous peer review

- Open access: articles freely available online

- High visibility within the field

Retaining the copyright to your article

Submit your next manuscript at $>$ springeropen.com 